\title{
Experience moderator effect on the variables that influence intention to use mobile learning
}

\author{
Ayad Shihan Izkair, Muhammad Modi Lakulu \\ Department of Computing, Sultan Idris Education University, Upsi, 35900 Tanjong Malim, Perak, Malaysia
}

\begin{tabular}{|c|c|}
\hline Article Info & ABSTRACT \\
\hline Article history: & The study has two objectives, first is exploring the variables that affect the \\
\hline Received Mar 18, 2021 & $\begin{array}{l}\text { intention to use mobile learning and second is investigating the experience } \\
\text { moderator effect on the variables that influence intention to use mobile }\end{array}$ \\
\hline Revised Jul 29, 2021 & learning in higher education institutions (HEI) in Iraq. Then formulate a \\
\hline Accepted Aug 13, 2021 & $\begin{array}{l}\text { model for intention to use mobile learning. A questionnaire has been } \\
\text { conducted in this research for collecting the feedback from the participants. }\end{array}$ \\
\hline Keywords: & $\begin{array}{l}\text { The findings confirmed that social influence (SI), performance expectancy } \\
\text { (PE), "facilitating conditions" (FCs), effort expectancy (EE) and }\end{array}$ \\
\hline Experience moderator & $\begin{array}{l}\text { "satisfaction" (SA) have an important influence on the intention to use mobile } \\
\text { learning. But, this study has rejected the "personal innovativeness" (PINN) }\end{array}$ \\
\hline Intention to use & factor as it was found not important. Furthermore, the study has confirmed \\
\hline Mobile learning & that the experience moderator variable has an influence of EE, SI, and PE on \\
\hline UTAUT & $\begin{array}{l}\text { the intention to use mobile learning. This study is significant to the field of } \\
\text { discipline as it will provide a roadmap for HEI to recognize the factors that } \\
\text { affect the intention to use mobile learning. }\end{array}$ \\
\hline
\end{tabular}

This is an open access article under the CC BY-SA license.

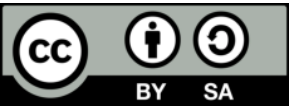

\section{Corresponding Author:}

Muhammad Modi Lakulu

Department of Computing

Sultan Idris Education University

Upsi, 35900 Tanjong Malim, Perak, Malaysia

Email: modi@fskik.upsi.edu.my

\section{INTRODUCTION}

The main objective of this research is to explore the variables that affect the intention to use mobile learning in addition to formulating a model for intention to use mobile learning in HEI in Iraq. Mobile learning becomes an important part of learning and education for facilitatig learning experiences [1]. Mobile learning has historically been additional powerfully developed among the informal education fields. However, throughout the previous years, there's an increasing interest in the mixing of those innovations in formal education. One of the major components that required to successfully accomplish this integration method, is that the mobile technologies acceptance by the teachers [2]. The growing enlargement of mobile technology in community has become a fact [3].

In some countries, the governments have accomplished the specified level of satisfaction in giving mobile services to their voters though at the same time a number of the countries are still behind from the specified level [4], [5] study mentioned the affordances of mobile application include; cost efficient, able to motivate students, suitable for drill and practice exercises and support personal learning environment. Moreover in general mobile application support various approach of learning, both formal and informal [6]. Several organizations have focused their efforts on using the emerging digital technology for their users [7]. 


\section{RELATED WORKS}

This part will discuss with details the model of the unified theory of acceptance and use of technology (UTAUT), and the intention to use also the variables affect the intention to use of mobile learning in previous studies. Moreover, it will argue the experience moderation influence on the variables that affect the intention to use mobile learning.

\subsection{The model of the unified theory of acceptance and use of technology}

The model of the UTAUT was developed and proposed by investigators via the combination of eight main theories in behavioral prediction. Regarding to UTAUT it is consists of four factors: performance expectancy; facilitating conditions; social influences and effort expectancy [8], [9] research is to investigate the variables that affect university users' intentions for mobile learning acceptance. According to UTAUT, this research proposes a model to investigate the variables that affect the acceptance of mobile learning in HEI and to examine if prior mobile devices experience has effect on the mobile learning acceptance. Tan et al. [10] research empirically explores the factors that affect the learner's intention for mobile learning adoption using the approach of hybrid structural equation modeling-artificial neural networks (SEM-ANN) in Malaysia.

\subsection{The variables affect intention to use}

They are multiple variables that affect the intention to use of mobile learning have been identified in previous studies. This research will focus on the important variables that affect intention to use.

\subsubsection{Performance expectancy}

Performance expectancy (PE) could be described as the level to which a user accepts using the data frame would support him to acquire benefit from the implementation of the work. Furthermore, they also point out that performance expectancy considers as the most great indicator of intention to use mobile learning [11]. "H1: Performance expectancy has a positive effect on intention to use of mobile learning."

\subsubsection{Effort expectancy}

Effort expectancy (EE) is characterized by the level of ease that linked to the use of the system [11]. To take full advantage of the framework, studies must accept the mobile learning framework is meeting their values and needs. Previous research [12] has demonstrated the crucial influence of the perceived ease of use on intention to use. "H2: Effort expectancy has a positive effect on intention to use of mobile learning."

\subsubsection{Social influence}

Individuals who are related to each other in community and change their behavior to a certain degree in understanding with individuals who deem it necessary or have a same social stat [13]. Social influence (SI) has a vital role in affecting the recognition of possible adopters. Since the degree of instability is high in early regulation of innovation allocations, possible clients tend to look for positive proof of employment findings from other social performers. The process is described as "influence to accept information from another as evidence about reality" [14]. Studies have indicated that experience has a moderating impact on the social influence on a learner's behavioural intention for using mobile learning [11]. "H3: Social influence has a positive effect on intention to use of mobile learning."

\subsubsection{Facilitating conditions}

A facilitating condition could be described as the degree to which a user believes that a specialized and organizational framework is able for supporting the use of unused innovation in agreement with [11]. facilitating conditions (FC) were also presented by UTAUT model and were categorized as "degree to which users believe that the necessary infrastructures exist to support the use of a technological system" [11]. FC could be everything that works successfully to implement an evaluation method such as technical or organizational support, knowledge, administrative resources. The study showed that Facilitating Conditions has a critical impact on intention to use [11]. "H4: Facilitating conditions has a positive effect on intention to use of mobile learning."

\subsubsection{Personal innovativeness (PINN)}

According to Poong et al. [15] study mentioned whether a person adopts long-term innovation based on her or his innovation. Previous researchers have discovered that individuals with high degrees of innovation resort to have higher degrees of behaviour intention for modern innovations adoption [16]. According to [17] study, a user with a high degree of innovation has the capability to overcome with uncertainties and is ready to face challenges. Often this is vital in dealing with the adoption of technology 
due the result of employing modern innovation is still obscure when it has not already been used. [17] study distinguished four degrees of innovations: early adopters, early majority, late majority and laggards. "H5: Personal innovativeness has a positive effect on intention to use of mobile learning."

\subsubsection{Satisfaction (SA)}

Mohammadi [18] study mentioned instead of selling, to supplying, or to serving, the major aim of every business is users satisfaction and satisfy and meet their needs [19]. Satisfaction can be described as the users' comprehension of the degree to which their desires, objectives and needs have been completely met and their overall vision of information system [20]. "H6: Satisfaction has a positive effect on intention to use of mobile learning."

\subsubsection{Intention to use (ITU) and actual use (AU)}

Intention to use could be also considered as an behavior [21]. Within the acceptance domain, previous studies have been investigated the contextual link between the intention to use and the actual use in mobile learning or e-learning such as [21]-[23]. In [21] study emphasizes the intention to use positively influence the actual use. Therefore, the intention to use has a positive relationship with the actual use. Actual use of a particular innovation is defined to be dependent upon the behaviour intention of a customer towards that innovation [24], [25]. "H7: Intention to use has a positive effect on actual use of mobile learning."

\subsection{Mobile experience moderator}

Mobile experience could be described as a generic expertise with mobile phones services for example mobile broadcasting, mobile shopping, short messaging service (SMS), mobile learning and mobile games and not as an expertise with one specific mobile phone favor. Generally, experience is expected to raise the certainty of customers in their capability to use and support computers that support the implementation of their mission. The findings from previous researches point out that a user's experience is vital for user's understanding, perceptions and attitudes in online learning and teaching environments.

Thus, it is important to think about how the differences can be seen in their confrontations using portable non-teaching exercises tools and how these talents could be exchanged within the learning approach. [11] study debates that experience could moderate the influence on intention to use. Moreover, [26] study confirmed the experience moderator has a positive influence on the link between the performance expectancy and the intention to use. This means, when the students have more experience, then they will achieve and accept the mobile learning. The experience moderates the influence of effort expectancy on intention to use and those influences reduce with experience. The impact of social influence on intention is conditioned on experience moderator included here for example the study discovered it to be unimportant when the data were analysed without the inclusion of experience moderator [11].

Zaremohazzabieh et al. [27] study indicated that the result showed that the experience has moderating influence on the relationships between the performance expectancy and effort expectancy within the behavioural intention to use mobile learning. Besides, previous studies recommends the experience would moderate the link between the social influence and intention to use. According to the [28] research, social influence seems as necessary as it was in the beginning phase of experience when the user initially uses the innovation.

"H8: Experience is a moderating variable influencing the effect of performance expectancy on intention to use of mobile learning."

"H9: Experience is a moderating variable influencing the effect of effort expectancy on intention to use of mobile learning."

"H10: Experience is a moderating variable influencing the effect of social influence on intention to use mobile learning."

\section{RESEARCH METHODOLOGY}

Research methodology represents the significant and main stage in the development of the research to assure important and systematic research into the phenomenon's examination. The objectives of the articulated research directed the researcher to embrace appropriate step by step approach to reach them.

\subsection{Research approach (quantitative)}

Quantitative approach characteristically indicates to integrated surveys that are managed for people or families, which are identified through a variety of forms of samples normally random samples [29], [30]. Quantitative data includes categories and numbers are ideally analyzed with the tools of statistical methods. This research uses the survey (questionnaire) for collecting the data required from the target group, and then 
analyzed by SPSS and AMOS software to propose the initial model. Of course, the imperative for developing a specific model is driven from the research gap in a specific area of research [31].

\subsection{Survey (questionnaire)}

Firstly, this study utilizes a quantitative approach, which is described by [32] as "Explaining phenomena by collecting numerical data that are analyzed using mathematically based methods". It has the collection of numerical data to clarify a specific phenomenon. The first data collection method is using a questionnaire (survey). The questionnaire is designed by using Google forms application, therefore the responses are been given online, which is convenient for the participants of colleges of IT. The participants are students or academic staff from the three governmental universities in middle of Iraq. The link of the online questionnaire has been sent to the participants by using email and Facebook groups. To support the concept of mobile learning and to encourage the participants to use mobile learning at anytime and anyplace.

\section{DATA ANALYSIS AND RESULTS}

The obtained data from the questionnaire will be analyzed using AMOS software and SPSS software to obtain descriptive statistical figures, frequencies and mean. Using SPSS, the missing value, outliers, normality, multicollinearity and non-response bias will be checked [33]. The AMOS will be used to conduct the main analysis of this study. AMOS has three main stage. First is the confirmatory factor analysis. In this stage each variable will be examined for factor loading and achieving the indices. The second stage is the measurement model. In this stage, all the variables together will be checked for validity and reliability. The last stage is the structural model. In this study, the hypotheses testing will be conducted.

\subsection{Outliers}

Outliers are unique observations that are far from the centre (mean value) of the data [34]. Hair et al. [34] study suggested to check the boxplots of the variables to identify the outliers. The boxplot in this study were checked for all the variables. A total of 9 responses were identified as outliers and they were removed. Removing 9 responses makes the complete and usable responses 314 (323-9=314). The boxplots show that there is no outliers after removing the nine responses.

\subsection{Normality}

According to [34], [35], the normality can be checked using two methods. The first method is to check the skewness and kurtosis. It is widely accepted that value of skewness and kurtosis less than \pm 2 are acceptable and lead to a conclusion that the data are normally distributed [36]. The second method is to examine the histograms of the variable. A normal distribution looks like a bell-shaped. In this study, the kurtosis and the skewness are presented in Table 1. The table displays the value of Skewness ranged between -.030 to -.525 . These values are less than \pm 2 . In addition, the values of Kurtosis ranged between -.415 and -1.128 which are below \pm 2 . As it can be seen in Table 1, the data is normally distributed and to confirm the normal distribution.

Table 1 . Normality analysis

\begin{tabular}{lcc}
\hline Variable & Skewness $< \pm 2$ & Kurtosis $< \pm 2$ \\
\hline Performance Expectancy & -.323 & -.762 \\
Effort Expectancy & -.374 & -.536 \\
Social Influence & -.182 & -.680 \\
Facilitating Condition & -.492 & -.491 \\
Personal Innovativeness & -.148 & -.799 \\
Satisfaction & -.310 & -.415 \\
Intention to Use & -.030 & -1.128 \\
Actual Use & -.138 & -.921 \\
\hline
\end{tabular}

\subsection{Structural model}

The third level of SEM-AMOS is the structural model. In this level, the hypothesis is tested and the $\mathrm{r}$-square of the model is presented. Figure 1 displays the structural model of this research. The R-square of the dependent variable intention to use is 0.60 indicating that the independent variables such as PE, SI, satisfaction, personal innovativeness, FC, and EE, were able to explain $60 \%$ of the variation in intention to use. In addition, the R-square of actual use is 0.44 indicating that $44 \%$ of the variation in actual use can be explained by intention to use. These values of R-square are acceptable and considered excellent as pointed 
out by Hair et al. [37], R-square value between 0.25 to 0.50 is considered good while R-square value between 0.50 to 0.75 are considered excellent. Figure 1 presents the structural model of this research. The mean score value was used to test the direct effect and moderation effect between the variables of this research. This is in line with several researchers such as [37]-[39] have used the mean to test the structural model.

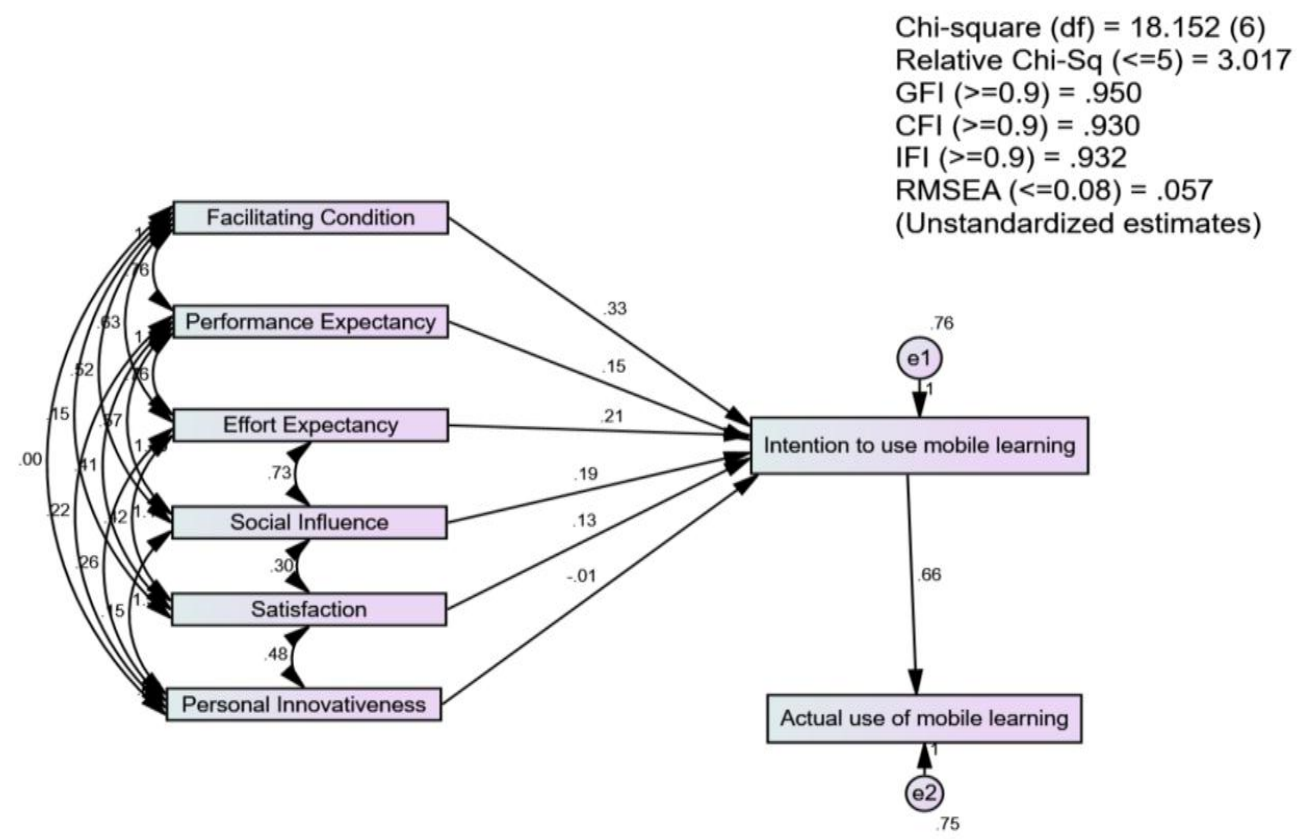

Figure 1. Structural model of direct effect

\subsection{Hypotheses testing}

The hypothesis of this study consists of seven direct effect hypotheses and three moderating hypotheses of experience. The following sections discuss first the direct effect hypotheses followed by the moderating effect of experience.

\subsubsection{Direct effect}

Seven direct effect hypotheses were developed in this research. Table 2 presents the findings of hypotheses testing for direct effect hypotheses. The table displays the hypothesis $(\mathrm{H})$, dependent variable (DV), path, independent variable (IV), estimate (B), standard error (S.E.), critical ratio (C.R.) or t-value (T), and level of significance $(\mathrm{P})$. A hypothesis is supported if the $\mathrm{P}$ or $\mathrm{p}$-value and also known as level of significance is less than 0.05 or the C.R. is greater than 1.96 as suggested by [37], [38].

Table 2. Results of direct effect hypotheses

\begin{tabular}{ccccccccc}
\hline H & DV & Path & IV & Estimate (B) & S.E. & C.R. & P \\
\hline H1 & ITU & $<---$ & PE & .151 & .049 & 3.097 & .002 & Supported \\
H2 & ITU & $<---$ & EE & .205 & .049 & 4.217 & $* * *$ \\
H3 & ITU & $<---$ & SI & .195 & .051 & 3.807 & $* * *$ \\
H4 & ITU & $<---$ & FC & .332 & .058 & 5.728 & $* * *$ \\
H5 & ITU & $<---$ & PINN & -.014 & .044 & -.311 & .756 & Supported \\
H6 & ITU & $<---$ & SA & .134 & .048 & 2.771 & .006 \\
H7 & AU & $<---$ & ITU & .660 & .042 & 15.812 & Rupported & Supported \\
\hline
\end{tabular}

Note: $* * *$ significance at the level of 0.001

Note: ITU: intention to use, PE: performance expectancy, SI: social influence, SA: satisfaction, AU: actual use, PINN: personal innovativeness, FC: facilitating condition, EE: effort expectancy."

All hypotheses are supported because $\mathrm{P}$ value is less than 0.05 or the C.R. is greater than 1.96. Only H5 is rejected because the P value (0.756) is greater than 0.05 and CR (-0.311) is less than 1.96. This means the personal innovativeness factor is not important and rejected in this study. 


\subsubsection{Moderating effect of experience}

The data was divided into high and low experience. Two datasets were extracted based on the mean score. In addition, two models were created; constrained and unconstrained. The following sections discuss the moderating effect of experience between PE, EE, and SI and intention to use mobile learning.

\subsubsection{Moderating effect of experience between PE and ITU}

The eighth hypothesis of this research predicted that experience will moderate the effect of PE on the intention to use mobile learning. The low and high experience data were examined. The findings of testing the moderating effect of both low and high experience showed the differences in the chi-square is more than 92 and it is greater than 3.84 and there is a moderating effect of both low and high experience between PE and intention to use mobile learning. Thus H8 is supported. To determine the type of the moderator, the paths were examined as shown in Table 3 and it is found that this moderator is partial. As it can be seen in Table 3, the effect of PE on ITU in low experience data is not significant. Thus, the moderation is partial.

Table 3. Type of moderator

\begin{tabular}{ccccccccc}
\hline Model & DV & Path & IV & Estimate & S.E. & C.R. & P & Label \\
\hline Low experience & ITU & $<---$ & PE & .119 & .067 & 1.765 & .078 & Not Supported \\
High experience & ITU & $<---$ & PE & .187 & .071 & 2.616 & .009 & Supported \\
$\begin{array}{l}\text { "H8: Experience is a moderating variable influencing the effect of performance expectancy on intention to } \\
\text { use of mobile learning" }\end{array}$ & & & & & Supported & \\
\hline
\end{tabular}

\subsubsection{Moderating effect of experience between EE and ITU}

The ninth hypothesis of this research expected that the effect of EE on ITU is moderated by experience. The hypothesis was tested, and findings show that the difference between chi-square of the two models (high and low) is more than 90 and this value exceed the recommended value of 3.84 indicating that experience has a moderating effect between EE and ITU. To determine the type of the moderation, the high and low path of experience were compared. It can be seen in Table 4 that both paths are significant indicating that the moderation is full. This confirms H9 that experience moderates the effect of EE on ITU.

Table 4. Type of moderator

\begin{tabular}{|c|c|c|c|c|c|c|c|c|}
\hline Model & DV & Path & IV & Estimate & S.E. & C.R. & $\mathrm{P}$ & Label \\
\hline Low experience & ITU & $<--$ & $\mathrm{EE}$ & .205 & .071 & 2.881 & .004 & supported \\
\hline High experience & ITU & $<---$ & $\mathrm{EE}$ & .216 & .067 & 3.246 & .001 & Supported \\
\hline $\begin{array}{l}\text { "H9: Experience } \\
\text { mobile learning" }\end{array}$ & $\mathrm{mo}$ & ating $v$ & ole in & effect of & ectanc & intenti & use of & Supported \\
\hline
\end{tabular}

\subsubsection{Moderating effect of experience between SI and ITU}

The tenth hypothesis of this research proposed that experience moderates the influence of SI on the intention to use. Low and high experience were tested. Result of the test shows the differences in the Chisquare is more than 75 and it is greater than 3.84. Thus, low and high experience have moderation effect between SI and ITU. The moderation of experience between SI and ITU is full. This is because the effect of SI on ITU in both models are significant as shown in Table 5. Thus, H10 is supported.

Table 5. Type of the moderator

\begin{tabular}{ccccccccc}
\hline Model & DV & Path & IV & Estimate & S.E. & C.R. & P & Label \\
\hline Low experience & ITU & $<---$ & SI & .158 & .068 & 2.318 & .020 & Supported \\
High experience & ITU & $<---$ & SI & .219 & .078 & 2.796 & .005 & Supported \\
"H10: Experience is a moderating variable influencing the effect of social influence on intention to use & Supported \\
mobile learning"
\end{tabular}

\subsection{Final model of intention to use mobile learning in HEI in Iraq}

The model produced by this work is based on the analysis findings of data collection of the survey. After testing, the final model has five factors which are "facilitating conditions", "performance expectancy", 
"effort expectancy", "social influence", and "satisfaction", which have positive influence on intention to use of mobile learning. See Figure 2 model of intention to use mobile learning.

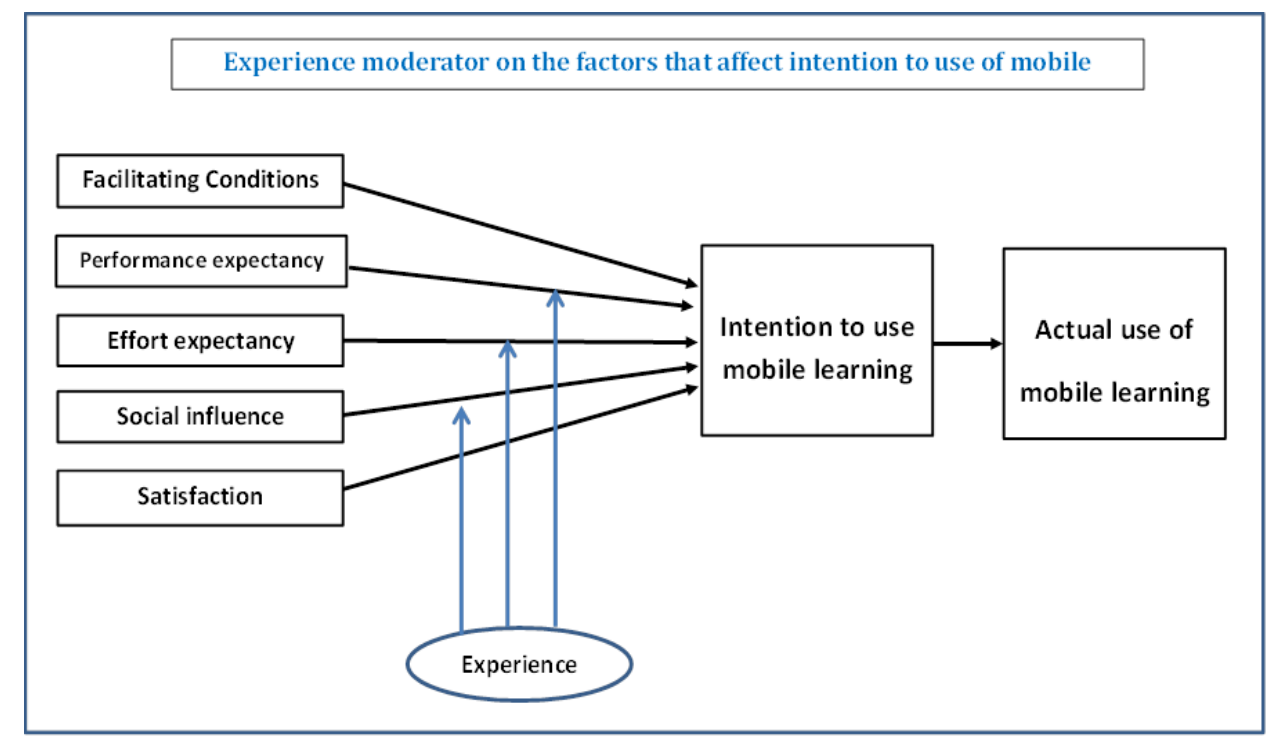

Figure 2. Final model of intention to use mobile learning

\section{CONCLUSION}

After data analysis, the result of this study discovered that only five factors are influencing intention to use mobile learning in HEI, the factors are "facilitating conditions", "performance expectancy", "effort expectancy", "social influence", and "satisfaction". In addition to that the study confirmed that intention to use mobile learning influencing actual use of mobile learning in HEI. Moreover, the study discovered that experience is a moderating variable influencing the effect of each of "performance expectancy", "effort expectancy", and "social influence" on intention to use of mobile learning in HEI. While this research has discovered that the personal innovativeness factor is not important and rejected. This study has important contributions to universities in the area of mobile learning field by presenting a model of mobile learning that could be used as reference for mobile learning at the higher education level. It is recommended for motivating users and enhancing social sense of mobile learning adopters, giving them with some options is suggested as follows. Suitable time arrangement and good management of application environment, potentiality of content printing and transmit by the method of application itself, potentiality of control all issues of the system while running, the existence of a stable available menu for learners, support the information and content with videos, sounds, images and expanding necessary designing educational information and content would address aesthetic criterions. The future studies could extend the research to explore other potential factors for example quality of services and personal innovativeness in future models in order to convey a comprehensive perception of customers' acceptance and use of mobile learning continually.

\section{REFERENCES}

[1] A. S. Izkair, M. M. Lakulu, and I. H. Mussa, "Intention to Use Mobile Learning in Higher Education Institutions: Review Paper," International Journal of Education Science Technology and Engineering, vol. 3, no. 2, pp. 78-84, 2020, doi: 10.36079/lamintang.ijeste-0302.157.

[2] J. C. Sánchez-Prieto, S. Olmos-Migueláñez, and F. J. García-Peñalvo, "Informal tools in formal contexts: Development of a model to assess the acceptance of mobile technologies among teachers," Computers in Human Behavior, vol. 55, pp. 519-528, 2016, doi: 10.1016/j.chb.2015.07.002.

[3] L. Briz-Ponce, A. Pereira, L. Carvalho, J. A. Juanes-Méndez, and F. J. García-Peñalvo, "Learning with mobile technologies-Students' behavior," Computers in Human Behavior, vol. 72, pp. 612-620, 2017, doi: 10.1016/j.chb.2016.05.027.

[4] N. D. Azeez and M. M. Lakulu, "Evaluation framework of M-government services success in Malaysia," Journal of Theoretical and Applied Information Technology, vol. 96, no. 24, pp. 8194-8226, 2018. 
[5] M. Mohamad, F. Maringe, and J. Woollard, "Mobile Learning in Malaysian Schools: Opportunities and Challenges of introducing teaching through mobile phones," International Journal for e-Learning Security, vol. 2, no. 1, pp. 133-137, 2012, doi: 10.20533/ijels.2046.4568.2012.0017.

[6] A. J. Mohamad, M. Lakulu, and K. Samsudin, "The development of mobile application for kindergarten early reading: challenges and opportunities," Journal of engineering and applied sciences, vol. 11, no. 3, pp. 380-383, 2016.

[7] A. J. Mohamad and M. M. Lakulu, "A framework of mobile educational application for kindergarten early reading," The International journal of Multimedia \& Its Applications, vol. 9, no. 4, pp. 113-119, 2017, doi :10.5121/ijma.2017.9610.

[8] R. A. Ali and M. R. M. Arshad, "Understanding intention to use mobile learning: a perspective of the extended unified theory of acceptance and use of technology," International Journal of Advanced And Applied Sciences, vol. 3, no. 7, pp. 81-88, 2016, doi: 10.21833/ijaas.2016.07.013.

[9] A. Abu-Al-Aish and S. Love, "Factors influencing students' acceptance of m-learning: An investigation in higher education," International Review of Research in Open and Distance Learning, vol. 14, no. 5, pp. 82-107, 2013, doi: 10.19173/irrodl.v14i5.1631.

[10] G. W. H. Tan, K. B. Ooi, L. Y. Leong, and B. Lin, "Predicting the drivers of behavioral intention to use mobile learning: A hybrid SEM-Neural Networks approach," Computers in Human Behavior, vol. 36, pp. 198-213, 2014, doi: 10.1016/j.chb.2014.03.052.

[11] V. Venkatesh, M. G. Morris, G. B. Davis, and F. D. Davis, "User acceptance of information technology: Toward a unified view," MIS Quarterly, vol. 27, no. 3, pp. 425-478, 2003, doi: 10.2307/30036540.

[12] R. Murali and J. Manimekalai, "Adoption of mobile technology in a learning environment," International Conference on Emerging Trends of Computer \& Information Technology (ICETCIT 2012), India, 2012, pp. 29-33,

[13] L. Rashotte, "Social Influence," Blackwell Encyclopedia Sociology, pp. 1-3, 2007.

[14] M. Deutsch and H. B. Gerard, "A study of normative and informational social influence upon individual judgement. Journal of Abnormal and," The journal of abnormal and social psychology, vol. 51, no. 3, pp. 629-636, 1955, doi: 10.1037/H0046408.

[15] Y. S. Poong, S. Yamaguchi, and J. I. Takada, "Investigating the drivers of mobile learning acceptance among young adults in the World Heritage town of Luang Prabang, Laos," Information Development, vol. 33, no. 1, pp. 57-71, 2017, doi: 10.1177/0266666916638136.

[16] R. Agarwal and J. Prasad, "A Conceptual and Operational Definition of Personal Innovativeness in the Domain of Information Technology," Information systems research, vol. 9, no. 2, pp. 204-215, 1998, doi: 10.1287/isre.9.2.204.

[17] E. M. Rogers, "Diffusion of innovations," Simon and Schuster, 2003.

[18] H. Mohammadi, "Social and individual antecedents of m-learning adoption in Iran," Computers in Human Behavior, vol. 49, pp. 191-207, 2015, doi: 10.1016/j.chb.2015.03.006.

[19] G. Dominici and F. Palumbo, "How to build an e-learning product: Factors for student/customer satisfaction," Business Horizons, vol. 56, no. 1, pp. 87-96, 2013, doi: 10.1016/j.bushor.2012.09.011.

[20] A. K. M. Islam, "Sources of satisfaction and dissatisfaction with a learning management system in post-adoption stage: A critical incident technique approach," Computers in Human Behavior, vol. 30, pp. 249-261, 2014, doi: 10.1016/j.chb.2013.09.010.

[21] A. Hassanzadeh, F. Kanaani, and S. Elahi, "A model for measuring e-learning systems success in universities," Expert Systems with Applications, vol. 39, no. 12, pp. 10959-10966, 2012, doi: 10.1016/j.eswa.2012.03.028.

[22] S. Alkhalaf, S. Drew, R. Alghamdi, and O. Alfarraj, "E-Learning system on higher education institutions in KSA : attitudes and perceptions of faculty members," Procedia-Social and Behavioral Sciences, vol. 47, no. Citc 2010, pp. 1199-1205, 2012, doi: 10.1016/j.sbspro.2012.06.800.

[23] M. Chow, D. K. Herold, T. M. Choo, and K. Chan, "Extending the technology acceptance model to explore the intention to use Second Life for enhancing healthcare education," Computers \& Education, vol. 59, no. 4, pp. 11361144, 2012, doi: 10.1016/j.compedu.2012.05.011.

[24] F. D. Davis, R. P. Bagozzi, and P. R. Warshaw, "User Acceptance of Computer Technology: A Comparison of Two Theoretical Models," Management Science, vol. 35, no. 8, pp. 982-1003, 1989, doi: 10.1287/mnsc.35.8.982.

[25] S. Iqbal and Z. A. Bhatti, "What drives m-learning? An empirical investigation of university student perceptions in Pakistan," Higher Education Research \& Development, vol. 36, no. 4, pp. 730-746, 2017, doi: 10.1080/07294360.2016.1236782.

[26] Y. Cruz, I. Boughzala, and S. Assar, "Technology acceptance and actual use with mobile leraning: First stage for studying the influence of learning styles on the behavioral intention," in Proceedings of the 22th European Conference on Information Systems (ECIS) 2014, Tel-Aviv, Israel, 2014, pp. 0-16.

[27] Z. Zaremohazzabieh, B. A. Samah, S. Z. Omar, J. Bolong, and H. A. M. Shaffril, "Fisherman's acceptance and use of information and communication technology integration in Malaysia. Exploring the moderating effect of age and experience," Journal of applied sciences, vol. 14, no. 9, pp. 873-882, 2014, doi: 10.3923/jas.2014.873.882.

[28] U. Varshney and R. Vetter, "Mobile commerce: Framework, applications and networking support," Mobile Networks and Applications, vol. 7, no. 3, pp. 185-198, 2002, doi: 10.1023/A:1014570512129.

[29] N. Dudwick, K. Kuehnast, V. N. Jones, and M. Woolcock, "Analyzing Social Capital in Context: A Guide to Using Qualitative Methods and Data," World Bank Institute, Washington, 2006. 
[30] L. T. Choy, "The Strengths and Weaknesses of Research Methodology: Comparison and Complimentary between Qualitative and Quantitative Approaches," IOSR Journal of Humanities and Social Science, vol. 19, no. 4, pp. 99104, 2014, doi: 10.9790/0837-194399104.

[31] N. M. Husain, M. M. Lakulu, and S. Sarkawi, "The Need for a Competency Model of Programming Teachers : a Need Analysis Survey," International Journal of Scientific and Research Publications, vol. 7, no. 6, pp. 265-269, 2017.

[32] M. Aliaga and B. Gunderson, "Introduction to Quantitative research. Doing Quantitative Research in Education with SPSS," Thousand Oaks, CA Sage Publication, pp. 1-11, 2000.

[33] R. K. Yin, "Case Study Research: Design and Methods (4th edition)," Thousand Oaks, CA Sage Publication, 2009, doi: $10.33524 /$ cjar.v14i1.73.

[34] J. F. Hair, T. M. Hult, C. M. Ringle, and M. Sarstedt, "A primer on partial least squares structural equation modeling," 2nd edition, Thousand Oakes, 2017.

[35] J. Pallant, "SPSS survival manual: a step by step guide to data analysis using SPSS," $7^{\text {th }}$ Edition, CRC Press, 2016.

[36] D. George and P. Mallery, "SPSS for Windows step by step: A simple guide and reference," $4^{\text {th }}$ Edition, (Electronic) LA-eng PT-Journal Article SB-IM. no. 1365-2141, 2008.

[37] J. F. Hair, R. E. Anderson, B. J. Babin, and W. C. Black, "Multivariate Data Analysis: A global perspective," 7th edition, NJ: Pearson, 2010.

[38] Z. Awang, "A Handbook on Structural Equation Modeling for Academicians and Practitioner," 1st edition, MPWS Rich Resources, Bandar Baru Bangi, kuala lumpur, Malaysia, 2014.

[39] P. B. Lowry and J. Gaskin, "Partial Least Squares (PLS) Structural Equation Modeling (SEM) for Building and Testing Behavioral Causal Theory: When to Choose It and How to Use It," in IEEE Transactions on Professional Communication, vol. 57, no. 2, pp. 123-146, June 2014, doi: 10.1109/TPC.2014.2312452.

\section{BIOGRAPHIES OF AUTHORS}

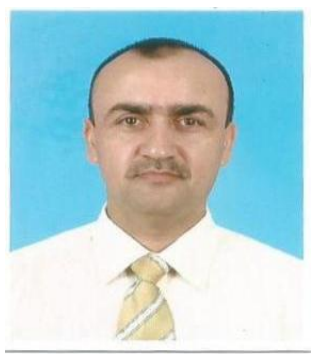

Ayad Shihan Izkair is studying a PhD in information system and management at Faculty of Art, Computing \& Creative Industry in Sultan Idris Education University-Malaysia. He has master degree in IT from Universiti Tenaga Nasional (UNITEN)-Malaysia in 2015. His Bachelor in Computer Science that obtained from University of Technology-Iraq in 1994. He worked for many years in mutiple ICT positions in many countries such as Libya, UAE, Malaysia and Iraq. He worked for many years in international NGOs and United Nations. His research interests in mobile learning, and knowledge management."

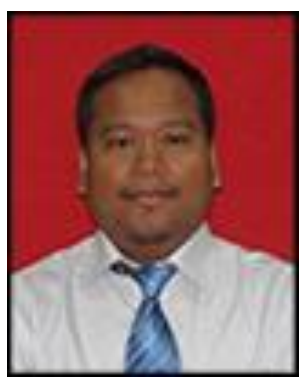

Muhammad Modi Lakulu is an Associate Professor and Deputy Dean (Research \& Innovation), Faculty of Art, Computing and Creative Industry (FACCI) at the Sultan Idris Education University. Moreover, $\mathrm{He}$ received his $\mathrm{PhD}$ degree in Computer Science (Knowledge Management) from the Universiti Putra Malaysia (UPM), in 2012. His research focuses on educational technology, software engineering and Information System. His research works have been published in journal, books and conference. He is an editorial board member of the Journal of ICT in Education." 